Provided for non-commercial research and education use. Not for reproduction, distribution or commercial use.



This article appeared in a journal published by Elsevier. The attached copy is furnished to the author for internal non-commercial research and education use, including for instruction at the authors institution and sharing with colleagues.

Other uses, including reproduction and distribution, or selling or licensing copies, or posting to personal, institutional or third party websites are prohibited.

In most cases authors are permitted to post their version of the article (e.g. in Word or Tex form) to their personal website or institutional repository. Authors requiring further information regarding Elsevier's archiving and manuscript policies are encouraged to visit:

http://www.elsevier.com/copyright 


\title{
Melanin-based coloration predicts natal dispersal in the barn owl, Tyto alba
}

\author{
Valentijn van den Brink*, Amélie N. Dreiss, Alexandre Roulin \\ Department of Ecology and Evolution, University of Lausanne, Switzerland
}

\section{A R T I C L E I N F O}

\section{Article history:}

Received 20 January 2012

Initial acceptance 20 March 2012

Final acceptance 11 June 2012

Available online 11 August 2012

MS. number: 12-00047R

\section{Keywords:}

animal personality

barn owl

breeding dispersal

local adaptation

natal dispersal

Tyto alba
Searching for a suitable breeding site is an important decision in the life of most animals. The decisions where to settle and how far to travel before doing so depend on many factors. Individual differences in dispersal distance could result from different strategies (e.g. specialists versus generalists), which might result in similar reproductive success in different habitats, or different competitive abilities to acquire a territory close to the natal site. The barn owl is polymorphic in melanic coloration, which is associated with many physiological and behavioural traits such as habitat choice, stress response and docility, raising the possibility that the coloration is also related to dispersal. We studied natal dispersal (from rearing site to site of first breeding attempt) and breeding dispersal (from one breeding site to the next) in barn owls using a long-term data set. Darker reddish individuals moved further than paler individuals during natal dispersal, but not during breeding dispersal. A cross-fostering experiment showed that the colour of the biological and foster parents had no influence on dispersal distance. The distance dispersed by parents and same-sex offspring was correlated, whereas natal and breeding dispersal were not repeatable within individuals, indicating that they are two different processes. Given that the distance travelled in natal dispersal appears to be heritable, the underlying genes might be coupled to those related to coloration. We discuss hypotheses to explain the potential adaptive function of the link between coloration and natal dispersal.

(c) 2012 The Association for the Study of Animal Behaviour. Published by Elsevier Ltd. All rights reserved.
Dispersal is an important aspect of population dynamics. The choice of a territory can, to a large extent, determine breeding success (Cody 1981), making it an important event in the life of an individual. The movements in the period preceding a breeding attempt are usually divided into two categories: natal dispersal, which is defined as the movements from the site where an individual was born to the site where it first breeds; and breeding dispersal, which is the distance between the two locations of successive breeding events (Greenwood \& Harvey 1982). The distances covered in natal dispersal are usually greater than those in breeding dispersal.

How individuals decide where to settle and how great a distance they will travel before settling depends on many factors. Individual strategies and environmental factors can explain interindividual variation in dispersal distances. Intraspecific competition for mates or other resources contribute greatly to dispersal (Johnson \& Gaines 1990; Perrin \& Mazalov 2000), so that individuals that are outcompeted have to move more. Body condition might also be of importance (Bowler \& Benton 2005; Clobert et al. 2009), although it

\footnotetext{
* Correspondence: V. van den Brink, Department of Ecology and Evolution, University of Lausanne, $\mathrm{CH}-1015$ Lausanne, Switzerland.

E-mail addresses: Valentijn.vandenbrink@unil.ch, valentijnb@gmail.com (V. van den Brink).
}

is not clear whether individuals in better condition are more or less likely to disperse than individuals in worse condition (Belthoff \& Dufty 1998; Meylan et al. 2002; Bonte \& De la Pena 2009). Local adaptation sometimes also plays an important role in the decision where and when to settle down (Edelaar et al. 2008). Some traits are better suited for different local environments and this would greatly influence the decisions individuals have to make when searching for a breeding location. Local adaptation can also impact the direction or the distance moved to a new nest site. For example, in response to predators or as a predator, individuals with different skin or plumage coloration might be better camouflaged in different habitats (Bortolotti 2006 cited in Hill \& McGraw 2006).

Another possibility that might lead to observed differences in dispersal behaviour is that the searching and moving behaviour is influenced by innate individual differences. Dispersal is a risky undertaking, with the possibility of predation during dispersal (Yoder et al. 2004) or of not being able to find a suitable breeding site in the unknown destination area. It is therefore not surprising that dispersers can differ in personality, physiology or morphology from nondispersers (Cote et al. 2010). When individual differences in behaviour are consistent and repeatable, they can be called temperament or animal personalities (Sih et al. 2004a; Reale et al. 2007). Suites of personality traits can also be correlated. For example, explorative and less explorative individuals are often divided into 'bold' and 'shy' categories, although these are extremes 
of a continuum (Reale et al. 2007). An example is the Trinidad killifish, Rivulus hartii, in which, when corrected for sex, predation risk and body size, individuals categorized as bold in behavioural tests in the laboratory dispersed further than shy individuals when returned to natural conditions (Fraser et al. 2001). Bold individuals are also more likely to migrate in roach fish, Rutilus rutilus (Chapman et al. 2011) and even in humans individuals with increased activity levels (a trait that is associated with boldness/ shyness; Reale et al. 2007) migrate more often (Jokela et al. 2008). Thus boldness and dispersal seem related to each other.

On a European scale, barn owls show a gradient in pheomelanic and eumelanic coloration from south to north (Roulin 2003). This gradient might reflect differences in the specific habitat requirements of the different colour morphs (Antoniazza et al. 2010). The females tend to disperse further than males (Taylor 1994) and we have already demonstrated that white nonpheomelanic males have a higher chance of being recruited in our local Swiss population than their darker reddish pheomelanic siblings (Roulin \& Altwegg 2007). Reddish individuals eat more voles and grow longer tails than whiter individuals, which eat more mice (Roulin 2004, 2006). Furthermore, it appears that whiter individuals breed more often in wooded habitats than reddish conspecifics (Charter et al. 2012; Dreiss et al. 2012). We also found a relationship between a eumelanic trait (diameter of black spots located at the tip of ventral feathers) and personality traits in our study population of barn owls (Van den Brink et al. 2012). The results already found in associations between colour and habitat choice and between colour and personality traits make this species suitable to investigate a possible relationship between dispersal behaviour and both pheomelanin- and eumelanin-based coloration. Since dispersal is sometimes also associated with personality traits we can assume that both personality and local adaptation might play a role in possible differences in barn owl dispersal distances.

We first studied the relationship between the individual colour and the natal dispersal of recruits: individuals born in the study area that ultimately also breed there. During the study period, cross-fostering experiments were performed, giving us the opportunity to study genetic and environmental influences on dispersal Second, we followed the movements between consecutive breeding attempts of individuals breeding in our study area during their breeding career, the breeding dispersal. We investigated whether differences in breeding dispersal distance between individuals were related to their melanic colour and several other traits such as habitat characteristics or life history traits such as breeding success, age at first breeding and wing and tail length. Natal and breeding dispersal take place in different life stages and therefore we might see differences in distance travelled and underlying factors causing the two types of dispersal. Finally, we investigated whether dispersal distance and/or coloration are also related to reproductive success. We discuss whether local adaptation, personality or other factors can explain colour-specific dispersal behaviour.

\section{METHODS}

\section{Study Species and Study Area}

Between 1994 and 2010 we studied a population of barn owls breeding in the Broye plain, a $25 \times 15 \mathrm{~km}$ area in western Switzerland $\left(46^{\circ} 49^{\prime} \mathrm{N}, 06^{\circ} 56^{\prime} \mathrm{E}\right)$. The Veterinary Service of the Canton of Vaud, Switzerland, authorized this study under licence number 1146, allowing us to take blood samples for DNA and to cross-foster nestlings. The Swiss Ornithological station, Sempach, Switzerland, authorized the ringing of individuals. This population breeds mostly in nestboxes placed on farms. The barn owl is a medium-sized owl with worldwide occurrence. It hunts mainly voles and mice in open agricultural areas (Glutz von Blotzheim 1987). It displays a distinct colour polymorphism ranging from spotless white to dark reddish pheomelanic and heavily marked with eumelanic black spots. Males are generally paler pheomelanic and show fewer and smaller black spots than females, although both sexes can display any phenotype (Roulin et al. 1998). The laying period ranges from February to August and the last fledglings appear as late as November. Clutches consist of two to nine eggs. Hatching occurs asynchronously with 2.5-day intervals, because the mother starts incubation directly after laying the first egg. This can result in an age difference of up to 3 weeks in a nest of nine offspring. After fledging at approximately 55 days of age, juveniles remain in the direct vicinity of their nest site for 1-2 months where they still receive regular feedings from their parents (Glutz von Blotzheim 1987; Taylor 1994). When individuals have become independent they will disperse and try to find their own breeding site. As in most bird species (Clarke et al. 1997), females generally disperse further than males, which might be driven by inbreeding avoidance (Greenwood \& Harvey 1982). The average migrating distances vary tremendously between populations, with mean distances ranging from within $10 \mathrm{~km}$ for a population in Britain to between 50 and $100 \mathrm{~km}$ for German and Dutch populations (Taylor 1994; Kniprath 2010). Dispersal distances appear related to food availability, with increasing distances in years with low vole densities (Taylor 1994). The distances reported here are mostly from recoveries of dead birds, which does not rule out the possibility that dispersal distances are inflated owing to transport between death and recovery (e.g. on the bumper of a car; Taylor 1994).

\section{Cross-fostering}

Between 1994 and 2010 we performed cross-fostering experiments, where nestlings from one nest were raised in another nest. Of the 185 studied individuals, 55 were cross-fostered. For more details see Roulin \& Dijkstra (2003) and Roulin (2006). Pairs of nests were matched by hatching date and some or all of the nestlings were swapped between them. We did this by immediately transporting nestlings by car from the nest of origin to the nest of rearing. During this procedure they were placed in a cloth bag, which was kept close to the body of one of the researchers to ensure the nestlings did not get cold during the time it took to drive between nest sites. The transport was always completed within $1 \mathrm{~h}$. This allowed us to study whether the dispersal behaviour was heritable by comparing dispersal distances between cross-fostered nestlings with those of their biological and foster parents. If local adaptation plays a large role in natal dispersal, we can expect crossfostered individuals not to be optimally adapted to the habitat where they were raised. This might then lead them to disperse further than noncross-fostered individuals.

\section{Assessment of Coloration}

At the age of fledging at about 55 days old, A.R. measured colour traits (pheomelanic coloration, number of eumelanic spots and eumelanic spot diameter) and biometric measurements for all nestlings. Adult individuals were measured each year during the breeding season with females being distinguished from males by the presence of a brood patch. For our analyses we used the measurements of an individual made in the same year as the year under investigation. The methods of measuring and the exact measurements taken are described in more detail in Roulin (1999). Colour traits are heritable, both spot diameter $\left(h^{2}=0.82\right.$; Roulin et al. 2010) and pheomelanic coloration $\left(h^{2}=0.81\right.$; Roulin \& 
Dijkstra 2003). For the adults we determined the age of individuals either by their moult pattern (for method see Taylor 1994; $N=192$ individuals) or directly if we had ringed the individual as a nestling $(N=177)$

\section{Individual Traits}

To demonstrate that a relationship between dispersal distance and colour is not inflated by other variables, we included a number of covariates in our statistical models. We included age rank in the natal nest, since the pronounced hatching asynchrony in the barn owl might influence the outcome of competition among siblings for nesting sites (first-born individual had rank 1, second-born rank 2, and so on). The second covariate was the number of fledglings in the nest of rearing, because the distance dispersed might increase with increasing number of siblings fledged, as this increases the chance of inbreeding and competition over nest sites if no dispersal takes place (Szulkin \& Sheldon 2008). Morphology can also influence migration behaviour (Paradis et al. 1998; Dawideit et al. 2009) and therefore we included the adult wing length and tail length in two separate models for natal dispersal and breeding dispersal. We did not assess body condition, because body mass at fledging (the only condition measure we have) is not an accurate predictor of survival and reproductive success, as it is not measured at the same age in most individuals and thus does not reflect condition at fledging (Roulin 2002). Two more traits were included for breeding dispersal only: whether a change of partner between two consecutive breeding attempts occurred and the number of partners in the breeding career, controlled for the total number of breeding attempts. We included these two traits, because a change of partner may induce dispersal and a high number of partners might also indicate dispersal tendency.

\section{Measuring Dispersal Distance}

We used the linear distance in $\mathrm{km}$ from the nest site of rearing to the breeding nest site for natal dispersal, or from the breeding site in one year to the site in the next year for breeding dispersal. We assumed that natal dispersal could occur in any direction, because other studies found no clear directionality in dispersal, other than determined by geographical features (Taylor 1994; Marti 1999; Matics 2003). We performed a $\log +1$ transformation on the dispersal distances to improve normality (Shapiro-Wilk's test for normality of the transformed variable: $P=0.43$ ). A second measure available to us was the number of nestboxes that were closer to the nestbox of rearing than the nestbox where the individual finally attempted to breed. This method does not qualitatively change the results (not shown), and therefore we focused on the linear distance as a measure of dispersal. For the breeding dispersal we calculated the distances between consecutive breeding locations in different years. If more than one attempt took place in the same year (about $10 \%$ of the pairs attempt to breed more than once), the distance between the first attempt of that year and the last attempt of the previous year was used. The average number of attempts during the recorded breeding career for males \pm SE was $3.5 \pm 0.2$ (range 1-14) and for females $3.3 \pm 0.1$ (range 1-12). In another paper we intend to analyse second broods in barn owls and to assess whether there is an association between coloration and whether a second clutch was produced in the same nestbox or in another nestbox.

Our measure of dispersal in a limited area has the potential bias that we may miss dispersal events from those individuals that disperse beyond the borders of our study area. The tail of the dispersal kernel might contain individuals that differ in their reproductive output (this could be different in a positive or negative direction). The ring recovery data are too fragmented, however, for us to make inferences about events outside our study area.

\section{Breeder Density and Dispersal Distances}

When analysing dispersal, simply calculating the distance dispersed is not an appropriate measure, because the number and the location of available nest sites can strongly influence the dispersal distance (Van Noordwijk 1984). Individuals in the centre of a study area are therefore more likely to pass more possible breeding sites before reaching the edge of the study area. An alternative method is to calculate the number of potential breeding sites an individual crosses before it reaches the site where it finally breeds (Mateos-Gonzàlez \& Senar 2012), but these data are unavailable in our study population, because we do not know the territory sizes and limits. Therefore, we decided to use a number of covariates in our models to take this problem into account and demonstrate that our results are robust. We included the distance from the nestbox of rearing to the centre of our study area and the number of nestboxes surrounding the breeding site as a proxy for the number of suitable territories nearby. We included the number of nestboxes present in a $2 \mathrm{~km}$ radius around the rearing nest site where the focal individual was raised or bred as an adult and hence from where it dispersed. The mean home range of breeding male owls in our population was shown to be 335 ha (range 93-804 ha), which would give a radius of slightly over $1 \mathrm{~km}$ (Arlettaz et al. 2010), but because there is large variation in home range sizes we decided to use a $2 \mathrm{~km}$ radius for our analyses (when using a narrower, $1 \mathrm{~km}$ radius our results do not change qualitatively). For both natal dispersal and breeding dispersal analyses we only considered individuals recaptured during a breeding attempt inside of our study area.

\section{Natal Dispersal of Parents and Offspring and Individual Dispersal Tendency}

Our long-term data set provided us with the opportunity to compare natal dispersal distances for 53 individuals that were recruited into our study population with the natal dispersal distances of their offspring that were also recruited locally. We compared dispersal distances of both parents with those of their offspring of both sexes. We also added cross-fostering status of the offspring to the model (i.e. raised by either biological or foster parents). We tested individual tendency to disperse by comparing first natal dispersal distance with breeding dispersal distance for the same individual and second breeding dispersal within the same individual. If dispersal is part of a behavioural type (Sih et al. 2004b), an individual that is more likely to disperse further during natal dispersal might also be more likely to disperse later in life. We calculated the Pearson correlation between the individual $\log +1$ transformed natal and breeding dispersal distances of 75 individuals for which both distances were available. For individual breeding dispersal distances we calculated repeatability from a linear mixed model with individual identity and year of birth as random variables. Significance was assessed by performing a likelihood ratio test on full and reduced models, following methods described in Nakagawa \& Schielzeth (2010).

\section{Habitat Characteristics}

We recorded a number of other characteristics of the breeding sites. Since reddish individuals are known to breed more often in open areas than paler individuals, which breed more frequently near forests (Charter et al. 2012; Dreiss et al. 2012), we also 
measured the amount of forested area in a $1.5 \mathrm{~km}$ radius around the nestbox of rearing (see Frey et al. 2011 for a detailed description of methods). If local adaptation plays a role in the natal dispersal movements, we can expect reddish individuals that were raised in a forested area to move further than if raised in a site where forests are less abundant, perhaps to reach an area similar to the nest site of rearing.

\section{Statistical Methods}

All statistical tests were performed with the program JMP 9.01 (SAS Institute, Cary, NC, U.S.A.). Dispersal distances were $\log +1$ transformed, since this improved normality strongly (Shapiro-Wilk's test for goodness-of-fit on transformed values: $P=0.49$ ). All tests are two tailed, nonsignificant effects were removed sequentially, nonsignificant interactions first and $P$ values $<0.05$ are considered significant.

\section{Natal dispersal}

We studied the natal dispersal distances for 185 individuals (116 males and 69 females) out of 3128 fledglings (5.9\%); the other fledglings either did not breed in our study area or did not survive until breeding. With the information from these individuals we then constructed general linear mixed models with the pheomelanic plumage coloration score of the individuals as the response variable. In initial models, eumelanic traits were also explored, but number of spots and spot diameter did not explain any variation in distances dispersed and thus we did not study these traits further. The dependent variable was the $\log +1$ transformed distance between the nest of rearing and the nest where the first breeding attempt took place. Identity of the biological mother was included as a random factor to account for nonindependence of nestlings born from the same parents ( 30 of 97 mothers produced more than one recruit into the population). Mother identity explains the most (54\%) variation in the final model. If we replace the biological mother with one of the other parents, however, the results (not shown) do not change qualitatively. We also included nest site identity as a random effect, to account for offspring originating from the same nest site, but possibly different parents. The other variables included in the model, including interactions with colour, are shown in Table 1.

Table 1

Model explaining variation in natal dispersal in relation to individual pheomelanic colour of fledgling barn owls

\begin{tabular}{lcrrl}
\hline Variable & Estimate & $d f(1, \mathrm{x})$ & $F$ ratio & $P$ \\
\hline Log distance to centre of area & $\mathbf{0 . 3 3}$ & $\mathbf{7 5 . 2}$ & $\mathbf{1 2 . 0 5}$ & $\mathbf{0 . 0 0 1}$ \\
Cross-fostered*Colour & $\mathbf{- 0 . 0 5 6}$ & $\mathbf{1 0 2 . 8}$ & $\mathbf{1 0 . 7 1}$ & $\mathbf{0 . 0 0 1}$ \\
Colour & $\mathbf{- 0 . 0 3 9}$ & $\mathbf{9 8 . 8}$ & $\mathbf{4 . 9 5}$ & $\mathbf{0 . 0 2 8}$ \\
Cross-fostered & $\mathbf{- 0 . 0 3 0}$ & $\mathbf{9 9 . 3}$ & $\mathbf{0 . 9 3}$ & $\mathbf{0 . 3 4}$ \\
Wing length as adult & $\mathbf{- 0 . 0 0 8}$ & $\mathbf{1 0 3 . 9}$ & $\mathbf{4 . 1 4}$ & $\mathbf{0 . 0 4 5}$ \\
Age at first breeding & 0.020 & 64.1 & 0.62 & 0.43 \\
No. of sites within 2 km & -0.006 & 83.7 & 0.72 & 0.40 \\
Forest cover & -0.00005 & 43.7 & 0.72 & 0.40 \\
Sex & -0.015 & 81.3 & 0.48 & 0.49 \\
Age rank in nest of rearing & 0.005 & 56.2 & 0.06 & 0.81 \\
Wing length as adult*Colour & -0.003 & 86.5 & 1.52 & 0.22 \\
Age at first breeding*Colour & -0.019 & 83.2 & 1.59 & 0.21 \\
Log distance to centre of area*Colour & -0.057 & 76.9 & 0.41 & 0.52 \\
Sex'Colour & -0.015 & 78.4 & 0.35 & 0.56 \\
Forest cover*Colour & $<0.00001$ & 60.8 & 0.20 & 0.65 \\
Age rank in nest of rearing*Colour & 0.006 & 77.7 & 0.19 & 0.67 \\
No. of sites within 2 km*Colour & -0.001 & 87.0 & 0.04 & 0.85 \\
\hline
\end{tabular}

Significant terms and terms involved in significant interactions are written in bold and kept in the final model. Presented are parameter estimates, degrees of freedom, $F$ ratios and $P$ values for fixed effect terms. Terms removed from the model are in order of removal, the last removed on the top.

\section{Breeding dispersal}

We only considered adult individuals that had attempted breeding more than once in the study area, which allowed us to measure the distance between two consecutive breeding sites. Our sample consisted of those recruits used for the natal dispersal analyses that bred more than once $(N=75)$ and the individuals that we ringed as adults or that were ringed outside the study area by amateur ornithologists and later dispersed to our study area to breed there $(N=295)$. This resulted in a total of 369 individuals breeding more than once out of 976 ringed individuals that attempted to breed at least once in our study area. We used the $\log +1$ transformed distance between boxes in consecutive years as the response variable, thus the distance for an individual that bred in the same location twice was zero here. We included the identity of the individual and the year of birth as two random variables (explaining $17 \%$ and $4 \%$ of variation, respectively) to account for more than one breeding attempt of each individual (mean number of attempts $\pm \mathrm{SE}=3.4 \pm 0.1$; range 2-14 attempts). We include a change of partners between years, as unpublished data show that after a divorce, dispersal is likely to occur. We did not limit ourselves to divorce (where both partners are confirmed to be still alive the next year), but analysed all cases in which an individual had a new partner between years. For this model the variables and interactions included in the full model are presented in Table 2. As with natal dispersal, we did not find any effect of eumelanic traits in initial models and thus we focused on pheomelanic traits.

\section{Dispersal distance and reproductive success}

To assess the relationship between dispersal distance and reproductive success in the year following the dispersal event, we constructed models for the recruits, as well as for the breeding birds. Laying date, clutch size, the number of fledglings and whether or not any fledglings were produced were used as response variables in separate models. Predictors were the distance dispersed, sex, coloration (pheomelanic or spot diameter) and the interactions between these traits. Identity of the mother and year were included as random variables in the model for the recruits (explaining $14 \%$ and $2 \%$ of variance, respectively). The density of

Table 2

Model explaining variation in breeding dispersal of adult barn owls

\begin{tabular}{lcccc}
\hline Variable & Estimate & $d f(1, \mathrm{x})$ & $F$ ratio & $P$ \\
\hline Change of partner & $-\mathbf{0 . 1 0 8}$ & $\mathbf{8 5 7 . 2}$ & $\mathbf{1 4 3 . 7 0}$ & $<\mathbf{0 . 0 0 0 1}$ \\
Sex & $-\mathbf{0 . 0 7 2}$ & $\mathbf{2 7 6 . 3}$ & $\mathbf{4 9 . 0 0 7}$ & $\mathbf{< . 0 0 0 1}$ \\
Sex ${ }^{*}$ Change of partner & $-\mathbf{0 . 0 6 6}$ & $\mathbf{8 5 6 . 6}$ & $\mathbf{5 4 . 2 9}$ & $<\mathbf{0 . 0 0 0 1}$ \\
No. of sites within $\mathbf{2} \mathbf{~ k m}$ & $\mathbf{0 . 0 1 1}$ & $\mathbf{4 7 5 . 8}$ & $\mathbf{8 . 2 2}$ & $\mathbf{0 . 0 0 4}$ \\
Age & $\mathbf{- 0 . 0 1 2}$ & $\mathbf{3 8 6 . 7}$ & $\mathbf{6 . 6 9}$ & $\mathbf{0 . 0 1}$ \\
Forest cover & 0.000 & 363.1 & 3.00 & 0.09 \\
Log distance to centre of area & -0.063 & 295.2 & 1.88 & 0.17 \\
Colour & 0.007 & 272.1 & 1.03 & 0.31 \\
Age at first breeding & 0.009 & 205.7 & 0.91 & 0.34 \\
No. of partners & 0.006 & 216.8 & 0.47 & 0.49 \\
No. of breeding attempts & -0.004 & 188.8 & 0.20 & 0.65 \\
Sex Colour & -0.008 & 28.6 & 1.17 & 0.28 \\
Age*Colour & 0.002 & 573.8 & 0.61 & 0.44 \\
No. of partners*Colour & -0.005 & 255.3 & 0.77 & 0.38 \\
Log distance to centre of area*Colour & -0.023 & 268.5 & 0.78 & 0.38 \\
No. of sites within 2 km*Colour & -0.002 & 500.5 & 0.85 & 0.36 \\
Age at first breeding*Colour & -0.005 & 430.2 & 0.43 & 0.51 \\
Forest cover*Colour & -0.00002 & 521.3 & 0.22 & 0.64 \\
Change of partner*Colour & -0.002 & 769.8 & 0.09 & 0.77 \\
No. of breeding attempts*Colour & 0.002 & 356.5 & 0.09 & 0.76 \\
\hline
\end{tabular}

Significant terms and terms involved in significant interactions are written in bold and kept in the final model. Presented are parameter estimates, degrees of freedom, $F$ ratios and $P$ values for fixed effect terms. Terms removed from the model are in order of removal, the last removed on the top. 
nestboxes around the site of breeding was included to account for possible competition for breeding sites. The age at the first breeding attempt and the distance from the box of rearing to the centre of the study area were also included.

\section{Natal dispersal distance of parents and offspring}

We modelled the log-transformed offspring natal dispersal distance on the same-sex parent natal dispersal distance with a mixed model with restricted maximum likelihood. Six adults were biological parents of more than one recruit and therefore we included parent identity as a random factor in our model. Because these recruits were always raised in the same year and the same nest (the nest of origin), no other random variables were included. We included sex and whether or not an individual was crossfostered as fixed effects. We also tested dispersal of offspring and their opposite-sex parent with a similar model.

\section{RESULTS}

\section{Natal Dispersal}

We studied 185 individuals originating from 155 nests. The mean distance dispersed was $8.7 \pm 0.7 \mathrm{~km}$ for males and $11.2 \pm 0.9 \mathrm{~km}$ for females (mean for both sexes: $9.6 \pm 0.6 \mathrm{~km}$ ). The full model and statistics are presented in Table 1. When controlled for the distance from the centre of the study area where an individual was raised, which positively affected the dispersal distance, the final model showed that darker reddish pheomelanic individuals dispersed further than those that were paler. Individuals with shorter wings tended to move longer distances. The interaction between the colour and cross-fostering status was also significant. Upon closer inspection, only in noncross-fostered individuals $\left(N=130 ; F_{1,66.4}=22.3, P<0.0001 ;\right.$ Fig. 1 a) was there a significant relationship between natal dispersal and colour. In cross-fostered individuals $\left(N=55 ; F_{130.1}=0.46, P=0.50\right.$; Fig. $\left.1 \mathrm{~b}\right)$ no differences with colour were detectable. We investigated whether the dispersal distance was also related to the pheomelanic coloration of the parents, because colour is strongly heritable. We found no relationship between the coloration of the biological or foster parents and the natal dispersal distance of the recruits (all $P$ values $>0.29$ ).

\section{Natal Dispersal Distances of Parents and Offspring}

We found that natal dispersal distances of parents and same-sex recruits were similar (31 individuals: estimate $=0.43 \pm 0.18$, $F_{1,9.1}=5.9, P=0.03$; Fig. 2). Sex and cross-fostering had no effect $(P=0.19$ and $P=0.22$, respectively). When testing opposite-sex parents and offspring, we found no significant effects (all $P$ values $>0.23)$.

\section{Breeding Dispersal}

The full model and statistics for breeding dispersal are presented in Table 2. Adult females $(N=189)$ dispersed further than males $(N=184)$ between years $(3.5 \pm 0.2 \mathrm{~km}$ versus $1.8 \pm 0.1 \mathrm{~km})$, as did individuals that had a different partner compared to the year before (average: $3.1 \pm 0.2 \mathrm{~km}$ ). The greater the number of nestboxes surrounding the nestbox of the first year, the further individuals dispersed and the older individuals were the more site-faithful they became. The interaction between sex and change of partner was also significant and females dispersed almost twice as far as males in individuals that had changed partner $\left(F_{1,220}=92.2, P<0.0001\right)$. Both in females $\left(F_{1,429}=142.16, \quad P<0.0001\right)$ and in males $\left(F_{1,426}=18.14, \quad P<0.0001\right)$ individuals that changed partners

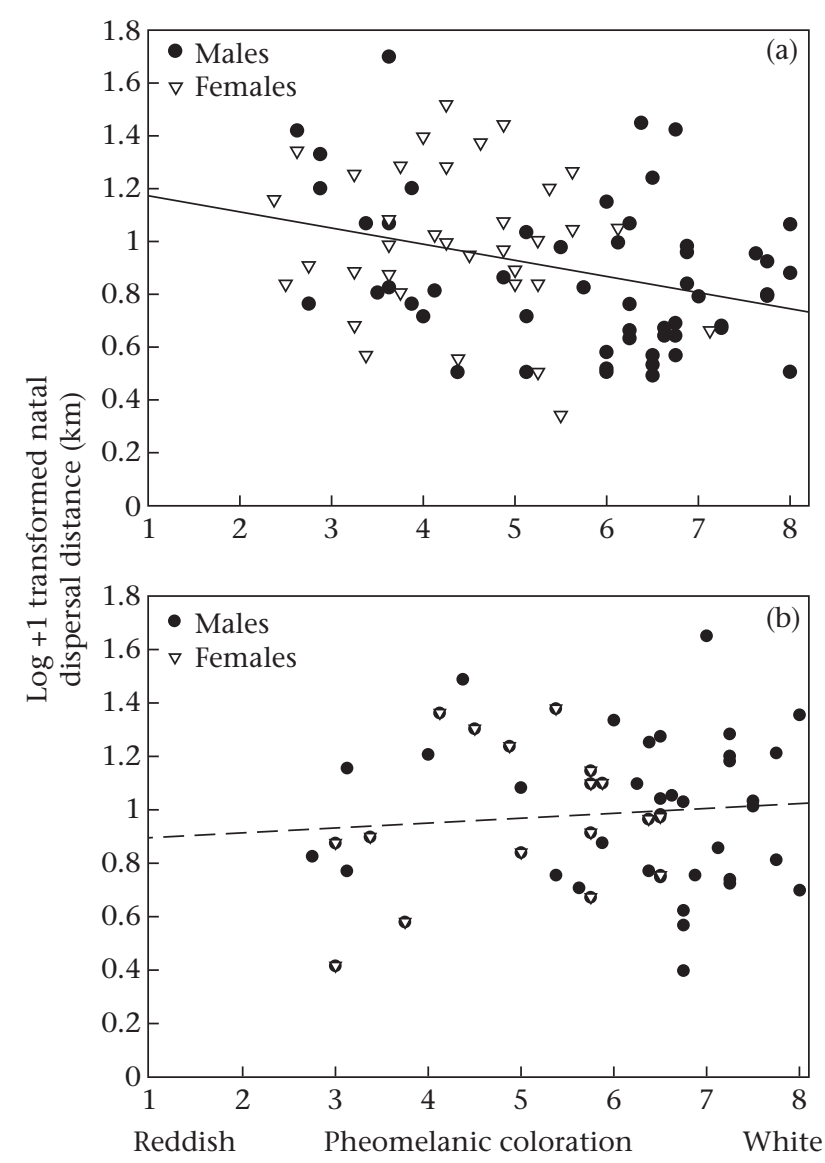

Figure 1. $\log +1$ transformed natal dispersal distance versus individual pheomelanic colour for (a) noncross-fostered and (b) cross-fostered fledgling barn owls. Regression line in (b) is drawn for illustrative purposes only.

between years dispersed further than individuals that did not (Fig. 3). No colour trait influenced the distance dispersed from year to year $(P$ values all $>0.48)$. The differences between individuals in distance dispersed were relatively small and to ensure we did not miss any possible relations because our statistical power was too low, we also built models with dispersal or not as a binomial response. The other variables included were the same as for the distance models. The results obtained from these models were

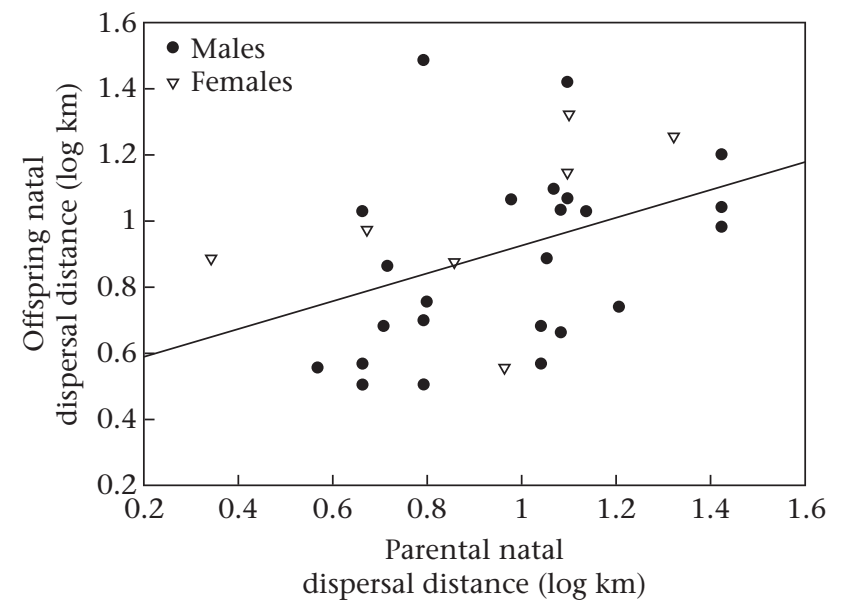

Figure 2. Relation between natal dispersal distance of parents and their same-sex offspring in the barn owl. 


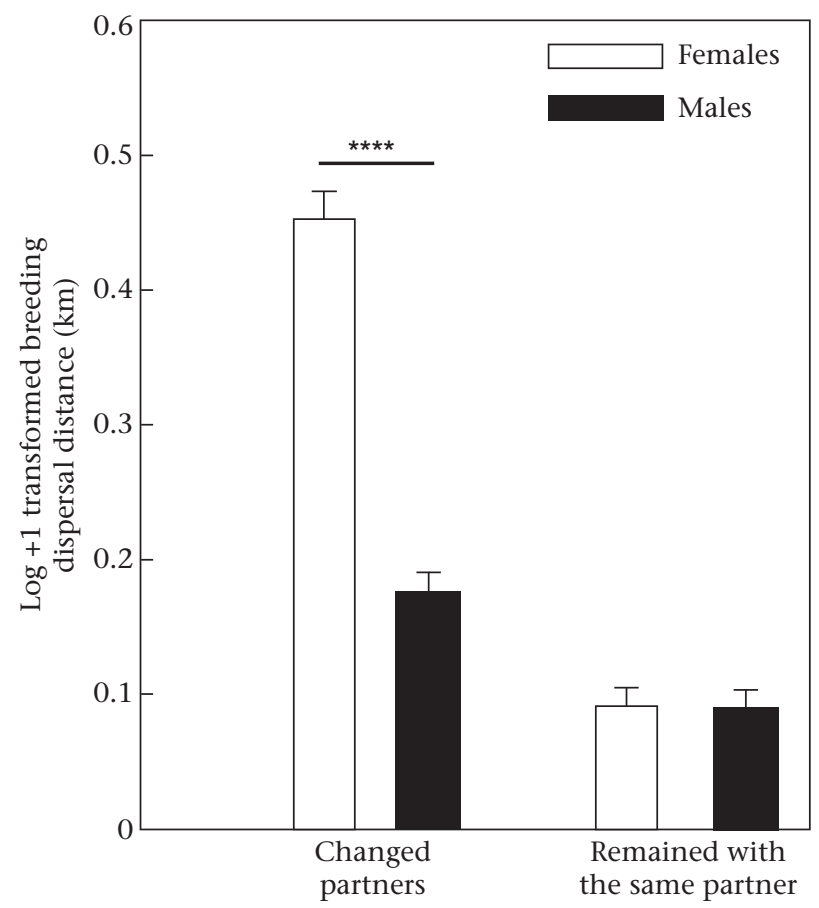

Figure 3. $\log +1$ transformed breeding dispersal distances + SE for male and female barn owls that changed partners or that remained with the same partner between consecutive years. The distances are shown on a log scale. Asterisks indicate significant differences between categories $(<0.0001)$.

qualitatively the same as those for the distance models (not shown).

\section{Within-individual Repeatability in Dispersal Behaviour}

We found no relationship between natal dispersal and the mean distance dispersed in all breeding dispersal events $(r=0.13$, $P=0.26$ ) for the 75 recruits of which we know both the natal and at least one breeding dispersal distance. Breeding dispersal was repeatable between years for the same individual when adult, however (adjusted repeatability: 0.26; confidence interval, CI: 0.19-0.33, $P<0.0001$; following Nakagawa \& Schielzeth 2010). This repeatability might seem low, but migration tendency is among the personality traits with lowest repeatability and these results fall within the reported range for the personality traits recorded (Bell et al. 2009).

\section{Dispersal Distance and Reproductive Success}

We did not find any relationship between dispersal distance and coloration with any of the reproductive parameters, either for the recruits in the first breeding attempt after natal dispersal or for the breeding birds in consecutive breeding attempts. For the recruits, a higher density of nestboxes surrounding the nestbox (regardless of occupation status) where the first breeding attempt took place meant that individuals started breeding later in the season $\left(F_{1,156.7}=4.7, P=0.03\right)$ and tended to result in fewer fledglings produced $\left(F_{1,152.2}=3.4, P=0.07\right)$.

\section{DISCUSSION}

In the barn owl, darker pheomelanic individuals moved greater distances between the site where they were raised and the site where they bred for the first time than paler individuals. In contrast, the degree of eumelanin-based coloration was not associated with breeding dispersal behaviour. Our results were robust because the relationship between natal dispersal and pheomelanin-based coloration remained significant even after controlling for a number of covariates. There was also no relationship between reproductive parameters and the distance dispersed in the preceding year, which might indicate that the differences we found in dispersal distance are caused by an innate tendency to disperse, which in turn might be linked to coloration. However, the reproductive parameters measured are for individuals that are fit enough to attempt breeding, since we could not measure dispersal distances of those individuals that did not manage to breed or bred outside of our study area. Interindividual variation in pheomelanin-based coloration is strongly heritable $\left(h^{2}=0.81\right.$; Roulin \& Dijkstra 2003) and dispersal distances are partially heritable (i.e. parents and offspring showed similar dispersal distances). Therefore, the relationship between natal dispersal and coloration, at least in part, may be genetically inherited.

We found an association between dispersal distance and coloration only for natal dispersal but not for breeding dispersal. We did not find a relation between the natal dispersal distance and the breeding dispersal distance, indicating that natal and breeding dispersal are two separate processes with different underlying motivations (Greenwood \& Harvey 1982). Generally, breeding individuals become more philopatric, as we also showed here, making the distances travelled between consecutive nesting sites shorter and more similar for all individuals and thereby reducing our power to detect differences. Males hold on to the nest sites (Taylor 1994; Roulin 1998), making a female that leaves her partner more likely to leave the nest as well and increasing the distance needed to find a suitable new partner and nest site. The strong effects of sex and of a change of partner on dispersal distance in the breeding dispersal seem to point out that there are factors other than coloration contributing strongly to breeding dispersal. One of those might be competition, since the number of nestboxes (which can be a proxy for possible competition for nest sites in the area) surrounding the site of breeding negatively influenced the number of fledglings produced and increased the laying date for the recruits.

We can only make inferences about those individuals that remained inside our study area and attempted to breed there and it could be that one colour is more likely than the other to disperse much further, biasing our results. This is a central issue in dispersal studies and cannot be easily remedied (Koenig et al. 1996). Given the strongly skewed dispersal kernels usually found in barn owls (Taylor 1994; Marti 1999; Kniprath 2010) it is nevertheless likely that most individuals remained and tried to breed inside the area. However, fitness results might be different for those few individuals in the tail of the kernel (Doligez \& Part 2008). Since we do not know where they went and what became of them we cannot speculate on how the results would have changed if we could have included all individual breeding attempts.

\section{Potential Functional Value of Colour-specific Dispersal}

In the following we discuss five nonmutually exclusive mechanisms that can explain the relationship between natal dispersal and pheomelanin coloration. A first possibility is that darker reddish individuals might be more sensitive to inbreeding than lightercoloured conspecifics leading them to disperse larger distances to reduce the risk of inbreeding (since colour influences many traits, physiological as well as behavioural, sensitivity to inbreeding could be one of them). Dispersal is often mentioned as a mechanism to avoid inbreeding and thus it might also play a role in our population. Such a relation could be formed through linkage 
disequilibrium, in which a trait related to sensitivity for inbreeding is also related to colour. Unfortunately, no data are yet available to test this hypothesis further. Second, whiter birds, which dispersed shorter distances in our study, might be favoured if they were locally adapted and in this case the results we found between colour and dispersal could be specific to our population. Assuming that the adaptation is to different habitats and assuming that parents breed in their optimal habitat, we would expect crossfostered nestlings to disperse further. However, we did not find a relationship between colour and dispersal distance for crossfostered individuals. This is slightly surprising since we could at least expect them to follow a pattern similar to noncross-fostered individuals if local adaptation played a role. We also did not find a difference in distance dispersed between cross-fostered and noncross-fostered individuals. We do not know what causes this difference but because we see different patterns, but not different distances, we believe local adaptation (alone) is unlikely to explain our results. Third, as proposed in Roulin \& Altwegg (2007), whiter birds could have a mating advantage (either in this population or regardless of population) and in this case our results could be applicable to other populations as well. If so, both males and females would enjoy such a mating advantage. Fourth, individuals may disperse greater distances if a dark coloration is in linkage disequilibrium with another phenotypic trait that is important for dispersal; a linkage might be selected if to disperse large distances individuals need to display simultaneously specific coloration and morphology. An example of such linkage disequilibrium was found in our study population where darker reddish males were mated with longer-tailed females and hence produced dark offspring with long tails (Roulin 2006). However, we only found that wing length, but not tail length, tended to be associated with natal dispersal distances but in an unexpected direction: longer-winged birds tended to disperse shorter distances, which is surprising given that longer wings might equal better flying abilities and thus easier dispersal (Dawideit et al. 2009; but see Paradis et al. 1998). Perhaps it has to do with manoeuvring ability in different habitats (e.g. forested versus more open), which would point towards an effect of local adaptation, but currently we cannot say whether this is a statistical artefact or a genuine difference. There is thus no evidence that darker birds disperse more because of genetically correlated traits that facilitate dispersal. This leads us to the fifth hypothesis advocating that individual differences in the distance dispersed could result from colour-specific personality. Dispersal is often linked to boldness and exploration (Budaev 1997; Dingemanse et al. 2003). It might be particularly beneficial for reddish birds to be explorative, which would lead to the observed difference. The phenotype of reddish birds could allow them to explore and settle in unknown areas more easily than white birds. As a consequence, they could invade already existing populations of whiter barn owls more quickly or settle in areas previously free of barn owls. Another option is that selection is being exerted on another (personality) trait that is genetically correlated with exploration or dispersal behaviour, but that there is no direct selection on reddish birds to be more explorative than white birds.

\section{Potential Proximate Mechanism Underlying Colour-Specific Dispersal}

The tendency of reddish birds to disperse larger distances than whitish individuals is associated with sex-specific strategies. Indeed, females are on average darker reddish than males and females disperse on average larger distances than males. Thus, expressing a reddish coloration may require sex-specific hormones that also trigger a range of female-specific behaviours including dispersal in the two sexes. In other words, individuals, males or females, that express a coloration that is typical of females (here reddish pheomelanic) tend to behave as females by dispersing long distances. Whether or not the association between female-specific morphology (i.e. melanin-based coloration) and dispersal behaviour is adaptive or the consequence of selection on another femalespecific behaviour remains an open question, but valuable to pursue. Indeed, we recently found that males and females displaying smaller black spots (a typical male plumage) are more aggressive than conspecifics displaying larger black spots (a typical female plumage; A. Roulin \& V. van den Brink, unpublished data). Thus, again the display of female-specific plumage is associated with the tendency to behave as female.

\section{Perspectives}

Our findings have brought up many new and exciting questions about the mechanisms that could explain the causes for the observed relationship between coloration and dispersal. We believe that it would be interesting to continue measuring personality traits such as boldness and exploratory behaviour in individual barn owls so that when more data become available we can construct pedigrees and calculate heritability estimates to investigate whether the personality traits and coloration measured as juveniles match dispersal behaviour later in life.

\section{Acknowledgments}

This study was made possible by a grant from the Swiss National Science Foundation (SNF) to A.R. (grants no. PPOA-102913 and 31003A_120517). We thank Martin Epars, Henri Etter and Bettina Almasi for help during fieldwork. We also thank two anonymous referees for their comments.

\section{References}

Antoniazza, S., Burri, R., Fumagalli, L., Goudet, J. \& Roulin, A. 2010. Local adaptation maintains clinal variation in melanin-based coloration of European barn owls (Tyto alba). Evolution, 64, 1944-1954.

Arlettaz, R., Krahenbuhl, M., Almasi, B., Roulin, A. \& Schaub, M. 2010. Wildflower areas within revitalized agricultural matrices boost small mammal populations but not breeding barn owls. Journal of Ornithology, 151, 553-564.

Bell, A. M., Hankison, S. J. \& Laskowski, K. L. 2009. The repeatability of behaviour: a meta-analysis. Animal Behaviour, 77, 771-783.

Belthoff, J. R. \& Dufty, A. M. 1998. Corticosterone, body condition and locomotor activity: a model for dispersal in screech-owls. Animal Behaviour, 55, 405-415. Bonte, D. \& de la Pena, E. 2009. Evolution of body condition-dependent dispersal in metapopulations. Journal of Evolutionary Biology, 22, 1242-1251.

Bortolotti, G. R. 2006. Natural selection and coloration: protection, concealment, advertisement or deception? In: Bird Coloration Vol. 2, Function and Evolution (Ed. by G. E. Hill \& K. J. McGraw), pp. 3-36. Cambridge, Massachussets: Harvard University Press.

Bowler, D. E. \& Benton, T. G. 2005. Causes and consequences of animal dispersal strategies: relating individual behaviour to spatial dynamics. Biological Reviews, 80, 205-225

Budaev, S. V. 1997. 'Personality' in the guppy (Poecilia reticulata): a correlational study of exploratory behavior and social tendency. Journal of Comparative Psychology, 111, 399-411.

Chapman, B. B., Hulthen, K., Blomqvist, D. R., Hansson, L. A., Nilsson, J. A., Brodersen, J., Nilsson, P. A., Skov, C. \& Bronmark, C. 2011. To boldly go: individual differences in boldness influence migratory tendency. Ecology Letters, 14, 871-876.

Charter, M., Peleg, O., Leshem, Y. \& Roulin, A. 2012. Similar patterns of local barn owl adaptation in the Middle East and Europe with respect to melanic coloration. Biological Journal of the Linnean Society, 106, 447-454.

Clarke, A. L., Saether, B. E. \& Roskaft, E. 1997. Sex biases in avian dispersal: a reappraisal. Oikos, 79, 429-438.

Clobert, J., Le Galliard, J. F., Cote, J., Meylan, S. \& Massot, M. 2009. Informed dispersal, heterogeneity in animal dispersal syndromes and the dynamics of spatially structured populations. Ecology Letters, 12, 197-209.

Cody, M. L. 1981. Habitat selection in birds: the roles of vegetation structure, competitors and productivity. Bioscience, 31, 107-113.

Cote, J., Clobert, J., Brodin, T., Fogarty, S. \& Sih, A. 2010. Personality-dependent dispersal: characterization, ontogeny and consequences for spatially structured populations. Philosophical Transactions of the Royal Society B, 365, 4065-4076. 
Dawideit, B. A., Phillimore, A. B., Laube, I., Leisler, B. \& Bohning-Gaese, K. 2009 Ecomorphological predictors of natal dispersal distances in birds. Journal of Animal Ecology, 78, 388-395.

Dingemanse, N. J., Both, C., van Noordwijk, A. J., Rutten, A. L. \& Drent, P. J. 2003. Natal dispersal and personalities in great tits (Parus major). Proceedings of the Royal Society B, 270, 741-747.

Doligez, B. \& Part, T. 2008. Estimating fitness consequences of dispersal: a road to 'know-where'? Non-random dispersal and the underestimation of dispersers' fitness. Journal of Animal Ecology, 77, 1199-1211.

Dreiss, A. N., Antoniazza, S., Burri, R., Fumagalli, L., Sonnay, C., Frey, C., Goudet, J. \& Roulin, A. 2012. Local adaptation and matching habitat choice in female barn owls with respect to melanic coloration. Journal of Evolutionary Biology, 25, 103-114.

Edelaar, P., Siepielski, A. M. \& Clobert, J. 2008. Matching habitat choice causes directed gene flow: a neglected dimension in evolution and ecology. Evolution, 62, 2462-2472.

Fraser, D. F. Gilliam, J. F. Daley, M. J., Le, A. N. \& Skalski, G. T. 2001. Explaining leptokurtic movement distributions: intrapopulation variation in boldness and exploration. American Naturalist, 158, 124-135.

Frey, C., Sonnay, C., Dreiss, A. \& Roulin, A. 2011. Habitat, breeding performance, diet and individual age in Swiss barn owls (Tyto alba). Journal of Ornithology, $152,279-290$.

Glutz von Blotzheim, U. N. 1987. Handbuch der Vögel Mitteleuropas. Wiesbaden: Aula-Verlag.

Greenwood, P. J. \& Harvey, P. H. 1982. The natal and breeding dispersal of birds. Annual Review of Ecology and Systematics, 13, 1-21.

Hill, G. E. \& McGraw, K. J. 2006. Bird Coloration, Volume 2: Function and Evolution. Cambridge, Massachusetts: Harvard University Press.

Johnson, M. L. \& Gaines, M. S. 1990. Evolution of dispersal: theoretical models and empirical tests using birds and mammals. Annual Review of Ecology and Systematics, 21, 449-480.

Jokela, M., Elovainio, M., Kivimaki, M. \& Keltikangas-Jarvinen, L. 2008 Temperament and migration patterns in Finland. Psychological Science, 19, 831-837.

Kniprath, E. 2010. Die Wanderungen der jungen Schleiereulen Tyto alba in Europa, eine Literaturübersicht. Eulenrundblik, 60, 56-65.

Koenig, W. D., Van Vuren, D. \& Hooge, P. N. 1996. Detectability, philopatry, and the distribution of dispersal distances in vertebrates. Trends in Ecology \& Evolution, 11, 514-517.

Marti, C. D. 1999. Natal and breeding dispersal in barn owls. Journal of Raptor Research, 33, 181-189.

Mateos-Gonzàlez, F. \& Senar, J. C. 2012. Melanin-based trait predicts individual exploratory behaviour in siskins, Carduelis spinus. Animal Behaviour, 83 229-232.

Matics, R. 2003. Direction of movements in Hungarian barn owls (Tyto alba): gene flow and barriers. Diversity and Distributions, 9, 261-268.

Meylan, S., Belliure, J., Clobert, J. \& de Fraipont, M. 2002. Stress and body condition as prenatal and postnatal determinants of dispersal in the common lizard (Lacerta vivipara). Hormones and Behavior, 42, 319-326.
Nakagawa, S. \& Schielzeth, H. 2010. Repeatability for Gaussian and non-Gaussian data: a practical guide for biologists. Biological Reviews, 85, 935-956.

Paradis, E., Baillie, S. R., Sutherland, W. J. \& Gregory, R. D. 1998. Patterns of natal and breeding dispersal in birds. Journal of Animal Ecology, 67, 518-536.

Perrin, N. \& Mazalov, V. 2000. Local competition, inbreeding, and the evolution of sex-biased dispersal. American Naturalist, 155, 116-127.

Reale, D., Reader, S. M., Sol, D., McDougall, P. T. \& Dingemanse, N. J. 2007. Integrating animal temperament within ecology and evolution. Biological Reviews, 82, 291-318.

Roulin, A. 1998. Formation des couples en hiver chez l'effraie des clochers Tyto alba en Suisse. Nos Oiseaux, 45, 83-89.

Roulin, A. 1999. Delayed maturation of plumage coloration and plumage spottedness in the barn owl (Tyto alba). Journal für Ornithologie, 140, 193-197.

Roulin, A. 2002. Short- and long-term fitness correlates of rearing conditions in barn owls Tyto alba. Ardea, 90, 259-267.

Roulin, A. 2003. Geographic variation in sexual dimorphism in the barn owl Tyto alba: a role for direct selection or genetic correlation? Journal of Avian Biology, 34, 251-258.

Roulin, A. 2004. Covariation between plumage colour polymorphism and diet in the barn owl Tyto alba. Ibis, 146, 509-517.

Roulin, A. 2006. Linkage disequilibrium between a melanin-based colour polymorphism and tail length in the barn owl. Biological Journal of the Linnean Society, 88, 475-488.

Roulin, A. \& Altwegg, R.2007. Breeding rate is associated with pheomelanism in male and with eumelanism in female barn owls. Behavioral Ecology, 18, 563-570.

Roulin, A. \& Dijkstra, C. 2003. Genetic and environmental components of variation in eumelanin and phaeomelanin sex-traits in the barn owl. Heredity, 90, 359-364.

Roulin, A., Richner, H. \& Ducrest, A. 1998. Genetic, environmental and conditiondependent effects on female and male ornamentation in the barn owl Tyto alba. Evolution, 52, 1451-1460.

Roulin, A., Altwegg, R., Jensen, H., Steinsland, I. \& Schaub, M. 2010. Sex-dependent selection on an autosomal melanic female ornament promotes the evolution of sex ratio bias. Ecology Letters, 13, 616-626.

Sih, A., Bell, A. \& Johnson, J. C. 2004a. Behavioral syndromes: an ecological and evolutionary overview. Trends in Ecology \& Evolution, 19, 372-378.

Sih, A., Bell, A. M., Johnson, J. C. \& Ziemba, R. E. 2004b. Behavioral syndromes: an integrative overview. Quarterly Review of Biology, 79, 241-277.

Szulkin, M. \& Sheldon, B. C. 2008. Dispersal as a means of inbreeding avoidance in a wild bird population. Proceedings of the Royal Society B, 275, 703-711.

Taylor, I. 1994. Barn Owls. Predator-Prey Relationships and Conservation. Cambridge: Cambridge University Press.

Van den Brink, V., Dolivo, V., Falourd, X., Dreiss, A. N. \& Roulin, A. 2012. Melanic color-dependent anti-predator behavior strategies in barn owl nestlings. Behavioral Ecology, 23, 473-480.

Van Noordwijk, A. J. 1984. Problems in the analysis of dispersal and a critique on its heritability in the great tit. Journal of Animal Ecology, 53, 533-544.

Yoder, J. M., Marschall, E. A. \& Swanson, D. A. 2004. The cost of dispersal: predation as a function of movement and site familiarity in ruffed grouse. Behavioral Ecology, 15, 469-476. 